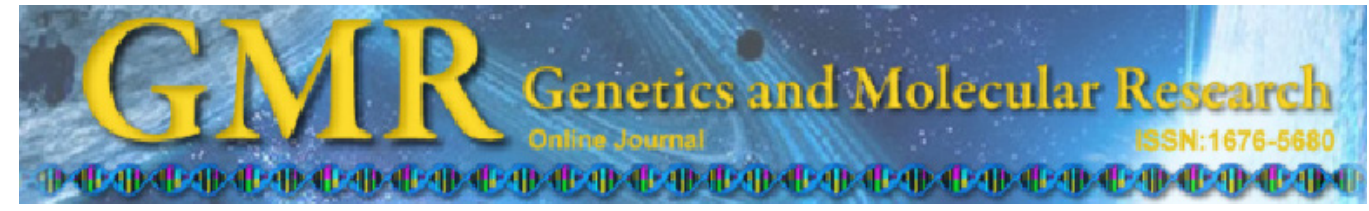

\title{
Analysis of microsatellite instability and loss of heterozygosity in ovarian cancer: a study in the population of Espírito Santo, Brazil
}

\author{
L.N.R. Alves ${ }^{1}$, E.V. Wolfgramm ${ }^{2}$, A.K. de Castro Neto ${ }^{2}$ and I.D. Louro ${ }^{1}$ \\ ${ }^{1}$ Núcleo de Genética Humana e Molecular, Departamento de Ciências Biológicas, \\ Centro de Ciências Humanas e Naturais, \\ Universidade Federal do Espírito Santo, Vitória, ES, Brasil \\ ${ }^{2}$ Serviço de Patologia, Hospital Santa Rita de Cássia, Vitória, ES, Brasil
}

Corresponding author: I.D. Louro

E-mail: iurilouro@yahoo.com

Genet. Mol. Res. 12 (2): 1996-2001 (2013)

Received November 20, 2012

Accepted May 2, 2013

Published June 14, 2013

DOI http://dx.doi.org/10.4238/2013.June.14.2

\begin{abstract}
Ovarian cancer is currently the most lethal gynecological malignancy in women. It is a heterogeneous and cytogenetically complex disease previously associated with genomic instability. Our purpose was to analyze microsatellite markers to determine patterns and levels of instability as well as possible correlations with histopathological parameters. Polymerase chain reaction was used to characterize microsatellite instability (MSI) and loss of heterozygosity (LOH) in 24 ovarian tumors at 12 microsatellite loci. A total of 11 samples displayed MSI or LOH. Only low-level MSI was found. Markers D5S346 and CYP11 showed the highest MSI and LOH frequencies. D17S250 LOH was significantly associated with tumor histological type $(\mathrm{P}=0.0003)$, and estrogen receptor $\alpha$ was also associated with tumor histological type $(\mathrm{P}=0.048)$ when a combined analysis of LOH and MSI was performed. Furthermore, LOH was observed in a greater number of markers compared with those displaying MSI. Thus, our results support that MSI is less common than $\mathrm{LOH}$ in ovarian cancers.
\end{abstract}

Key words: Genomic instability; MSI; LOH; Ovarian cancer 


\section{INTRODUCTION}

Ovarian cancer is currently the most lethal gynecological malignancy in women despite its low prevalence. Because this cancer is especially difficult to diagnosis and is often detected late, it has a small chance of cure. Approximately $75 \%$ of ovarian cancers are diagnosed at advanced stages, at which overall patient survival is usually <30\% (Huan et al., 2008; Inca, 2012).

Ovarian cancer is the 8th most common malignancy in women worldwide, affecting approximately 225,500 women and causing almost 140,200 cancer deaths per year (Jemal et al., 2011). This cancer is the 4th most frequent cause of cancer-related death in women in Europe and the United States (Bandiera et al., 2012). In Brazil, 5530 women were diagnosed with ovarian cancer in 2008, and 2982 women died from the disease (Ferlay et al., 2010). According to data from Instituto Nacional de Câncer (Brazilian National Cancer Institute), 6190 and 110 new cases of ovarian cancer are expected in Brazil and Espírito Santo State, respectively, in 2012 (Instituto Nacional de Câncer José Alencar Gomes da Silva, 2011).

The molecular pathogenesis of ovarian cancer is still poorly understood (Shen et al., 2006); however, it is believed that microsatellite instability (MSI) or loss of heterozygosity $(\mathrm{LOH})$ at various chromosomal locations is implicated (Plisiecka-Hałasa et al., 2008). MSI is defined as a size change in short tandem repeat sequences in a tumor compared with normal tissue from the same patient (Boland et al., 1998). It was first described in colorectal cancers and it has since been shown to play a significant role in several other cancers. The association of MSI and cancer has advanced the detection of cancer susceptibility, chemotherapy response, and prognosis (Sood et al., 2001). MSI at numerous loci in multiple cancers suggests that genetic instability is an important event in the progression of cancer (Galindo et al., 2011). In ovarian tumors, the reported incidence of MSI ranges from 5 to $50 \%$ depending on the markers and definition of MSI used (Sood et al., 2001).

$\mathrm{LOH}$ results from the random loss of 1 allele through deletion or gene conversion, leading to a putative tumor growth advantage (Ando et al., 2000; Powierska-Czarny et al., 2003). LOH is of particular importance because it enables recessive variants (especially in tumor suppressor genes) to influence tumor phenotype. High LOH frequency regions are candidates for harboring tumor suppressor genes (Skirnisdottir et al., 2012). In ovarian carcinoma, $\mathrm{LOH}$ is a common phenomenon, but some regions have high $\mathrm{LOH}$ frequencies without responsible candidate genes (Plisiecka-Hałasa et al., 2008). In the present study, we analyzed MSI and LOH in 24 ovarian carcinomas at 12 microsatellite loci to identify possible correlations between these events and histopathological tumor features.

\section{MATERIAL AND METHODS}

\section{Ethics}

This study was approved by the Research Ethics Committee of Universidade Federal do Espírito Santo (protocol No. CEP-002/09).

\section{Sample collection and DNA preparation}

Archival formalin-fixed, paraffin-embedded tissues from 24 ovarian cancer samples were obtained from the Department of Pathology of Santa Rita de Cássia Hospital, ES, Brazil, 
during 2009 and 2010. Tumor samples were collected by pathologist-guided, 3-mm punches of tumor blocks. Briefly, histology slides were prepared from formalin-fixed, paraffin-embedded tissues, stained with hematoxylin/eosin, and allowed to air dry. Tumor tissue was marked in hematoxylin/eosin-stained slides by the pathologist and aligned with the respective sample block so that the punch could be taken. Normal tissue control was also obtained from each block.

\section{DNA extraction}

DNA was obtained from $0.5-\mathrm{mm}$ punch slices through incubation at $58^{\circ} \mathrm{C}$ for 5 days in $0.5 \mathrm{M}$ Tris, $0.02 \mathrm{M}$ ethylenediaminetetraacetic acid, $0.01 \mathrm{M} \mathrm{NaCl}, 1 \mathrm{mg} / \mathrm{mL}$ proteinase $\mathrm{K}$, and $2 \%$ sodium dodecyl sulfate and subsequent organic extraction with phenol-chloroform. Finally, samples were eluted in $100 \mu \mathrm{L} 3 \mathrm{mM}$ Tris- $\mathrm{HCl}, \mathrm{pH} 7.5$ and $0.2 \mathrm{mM}$ ethylenediaminetetraacetic acid-sodium hydroxide, $\mathrm{pH} 8.0$.

\section{Microsatellite analysis}

Twelve markers [CYP19, CYP11, androgen receptor (AR), D8S135, D10S197, UGT1A1, D2S119, D3S1611, estrogen receptor (ER) $\alpha$, ER $\beta$, D5S346, and D17S250] were used in this study for MSI and LOH analysis. Polymerase chain reaction was performed in simplex reactions with a final volume of $15 \mu \mathrm{L}$ using cycling conditions specific to each primer pair. Polymerase chain reaction was performed using Taq Platinum ${ }^{\circledR}$ enzyme (Invitrogen, Carlsbad, CA, USA) according to manufacturer recommendations. Amplified fragments were resolved on $15 \%$ polyacrylamide gels at $160 \mathrm{~V}$ for $15 \mathrm{~h}$ and visualized after silver staining. MSI was detected when tumor alleles showed size contraction or expansion compared with normal tissue alleles. $\mathrm{LOH}$ was defined as a visible reduction of $50 \%$ or more in the normal band intensity. $\mathrm{LOH}$ was only detectable when normal alleles were heterozygous. Positive cases were reamplified for confirmation.

\section{Statistical analysis}

Statistical tests were performed using SPSS version 17.0 and Epi-Info version 3.5.1. Associations between MSI/LOH and tumor clinicopathological parameters were determined using the Fisher exact test and odds ratio with 95\% confidence intervals (95\% CIs). A significance value of $\mathrm{P}<0.05$ was used for all analyses.

\section{RESULTS}

DNA samples from 24 ovarian tumors and their adjacent normal tissue were analyzed using 12 short tandem repeat markers. Patients had a mean age of 55 years and a median of 54.5 years, ranging from 30 to 84 years (standard deviation, 13.8 years). Tumor samples consisted of 7 serous cystoadenocarcinoma (29.2\%), 1 mucinous cystoadenocarcinoma (4.2\%), 7 other malignant tumors (29.2\%), 5 metastatic ovarian tumors (20.8\%), and 4 borderline tumors $(16.6 \%)$.

\section{Genomic instability analysis}

Eleven of 24 ovarian tumors presented MSI or LOH. The highest MSI frequency was 
for marker D5S346, being 2.4\% the average MSI frequency for all markers (range: $0-13.6 \%$ ). CYP11 showed the highest LOH frequency, being $6.2 \%$ the average LOH frequency for all markers (range: $0-15.4 \%$ ).

Considering positivity at only 1 locus, frequencies of 16.7 and $25 \%$ were found for MSI and LOH, respectively (MSI: 4/24, 95\%CI $=1.78-31.62 \%$; $\mathrm{LOH}: 6 / 24,95 \% \mathrm{CI}=7.68$ $42.32 \%)$. Considering positivity at 2 loci, frequencies of MSI and LOH were both $4.17 \%$ $(1 / 24,95 \% \mathrm{CI}=0.00-11.97 \%)$. At 3 or more loci, MSI frequency dropped to $0 \%(0 / 24)$, whereas $\mathrm{LOH}$ frequency was $4.17 \%(1 / 24,95 \% \mathrm{CI}=0.00-11.97 \%)$.

Genomic instability characteristics, number of heterozygous loci, and the total number of samples analyzed for each marker are listed in Table 1. Genomic instability results by case are presented in Table 2.

Table 1. Loss of heterozygosity (LOH) and microsatellite instability (MSI) in ovarian cancer.

\begin{tabular}{|c|c|c|c|c|c|c|c|c|}
\hline \multirow[t]{2}{*}{ Markers } & \multicolumn{2}{|c|}{ MSI } & \multicolumn{2}{|c|}{$\mathrm{LOH}$} & \multicolumn{2}{|c|}{ Heterozygous } & \multicolumn{2}{|c|}{ Total } \\
\hline & $\mathrm{N}$ & $f$ & $\mathrm{~N}$ & $f$ & $\mathrm{~N}$ & $f$ & $\mathrm{~N}$ & $(\%)$ \\
\hline CYP19 & 0 & 0.000 & 0 & 0.000 & 16 & 0.800 & 20 & 0.833 \\
\hline CYP11 & 0 & 0.000 & 2 & 0.154 & 13 & 0.684 & 19 & 0.792 \\
\hline AR & 0 & 0.000 & 3 & 0.136 & 22 & 1.0 & 22 & 0.917 \\
\hline D8S135 & 0 & 0.000 & 0 & 0.000 & 5 & 0.208 & 24 & 1.0 \\
\hline D10S197 & 0 & 0.000 & 1 & 0.056 & 18 & 0.818 & 22 & 0.917 \\
\hline UGT1A1 & 0 & 0.000 & 0 & 0.000 & 9 & 0.409 & 22 & 0.917 \\
\hline D2S119 & 0 & 0.000 & 0 & 0.000 & 10 & 0.500 & 20 & 0.833 \\
\hline D3S1611 & 0 & 0.000 & 1 & 0.056 & 18 & 0.783 & 23 & 0.958 \\
\hline $\mathrm{ER} \alpha$ & 1 & 0.056 & 1 & 0.143 & 7 & 0.389 & 18 & 0.750 \\
\hline$E R \beta$ & 0 & 0.000 & 0 & 0.000 & 12 & 0.750 & 16 & 0.667 \\
\hline D5S346 & 3 & 0.136 & 3 & 0.150 & 20 & 0.909 & 22 & 0.917 \\
\hline D17S250 & 2 & 0.095 & 1 & 0.048 & 21 & 1.0 & 21 & 0.875 \\
\hline
\end{tabular}

Table 2. Loss of heterozygosity (LOH) and microsatellite instability (MSI) characterization by case.

\begin{tabular}{|c|c|c|c|c|c|c|c|c|c|c|c|c|}
\hline Tumor case & $\mathrm{AR}$ & CYP11 & CYP19 & D8S135 & D10S197 & UGT1A1 & D2S119 & D3S1611 & $\mathrm{ER} \alpha$ & $\mathrm{ER} \beta$ & D5S346 & $\mathrm{D} 17 \mathrm{~S} 250$ \\
\hline 1 & & & & & & & & & $\bullet$ & & 0 & \\
\hline 2 & & ○ & & & & & & & & $\mathrm{x}$ & & \\
\hline \multicolumn{13}{|l|}{3} \\
\hline 4 & & & & & & & & $\circ$ & & & ○ & \\
\hline 5 & & $\mathrm{x}$ & $\mathrm{x}$ & & & & $\mathrm{x}$ & & $\mathrm{x}$ & $\mathrm{x}$ & & \\
\hline 6 & & 0 & & & & & & & $x$ & $\mathrm{x}$ & & \\
\hline 7 & $\circ$ & & & & & & & & 0 & & ○ & 0 \\
\hline 8 & & & & & & & & & & $\mathrm{x}$ & & \\
\hline 9 & 0 & & & & & & & & & & $\bullet$ & $\bullet$ \\
\hline 10 & & $x$ & $x$ & & & & $\mathrm{x}$ & & $\mathrm{x}$ & $\mathrm{x}$ & $\mathrm{x}$ & $\mathrm{x}$ \\
\hline \multicolumn{13}{|l|}{11} \\
\hline 12 & & & & & & & & & & & $\bullet$ & \\
\hline 13 & $\mathrm{x}$ & $\mathrm{x}$ & $\mathrm{x}$ & & $\mathrm{x}$ & $\mathrm{x}$ & $\mathrm{x}$ & & $\mathrm{x}$ & $\mathrm{x}$ & & $\mathrm{x}$ \\
\hline \multicolumn{13}{|l|}{14} \\
\hline \multicolumn{13}{|l|}{15} \\
\hline \multicolumn{13}{|l|}{16} \\
\hline 17 & $\circ$ & & & & & & & & & & & \\
\hline \multicolumn{13}{|l|}{18} \\
\hline \multicolumn{13}{|l|}{19} \\
\hline 20 & & & & & & & & & & & & $\bullet$ \\
\hline \multicolumn{13}{|l|}{21} \\
\hline 22 & & & & & o & & & & & & & \\
\hline 23 & & $\mathrm{x}$ & & & & & & & $\mathrm{x}$ & $\mathrm{x}$ & $\bullet$ & \\
\hline 24 & $\mathrm{x}$ & $\mathrm{x}$ & $\mathrm{x}$ & & $x$ & $\mathrm{x}$ & $\mathrm{x}$ & $\mathrm{x}$ & $\mathrm{x}$ & $\mathrm{x}$ & $\mathrm{x}$ & $\mathrm{x}$ \\
\hline
\end{tabular}

Open dots = LOH; filled dots $=$ MSI; $x=$ non-informative. 


\section{Correlation between MSI/LOH and clinicopathological parameters}

We observed no statistically significant correlations between MSI/LOH and age at diagnosis. However, a significant correlation was observed between D17S250 LOH and mucinous cystoadenocarcinoma $(\mathrm{P}=0.0003)$. Furthermore, a combined analysis of $\mathrm{LOH}$ and MSI in $\mathrm{ER} \alpha$ showed an association with serous and mucinous cystoadenocarcinomas $(\mathrm{P}=0.048)$.

\section{Marker combination analysis}

To increase the efficiency of individual marker analysis, we examined markers in combinations and their possible correlation with ovarian cancer characteristics. Markers were selected according to their genomic instability frequencies - AR/ER $\alpha, D 5 S 346 / D 17 S 250$, and $\mathrm{AR} / \mathrm{ER} \alpha / \mathrm{D} 5 \mathrm{~S} 346 / \mathrm{D} 17 \mathrm{~S} 250$ - but we found no significant associations between marker group genomic instability and age at diagnosis or histological type $(\mathrm{P}>0.05)$.

\section{DISCUSSION}

Ovarian cancer is a heterogeneous and cytogenetically complex disease (Helleman et al., 2006; Skirnisdottir et al., 2012), exhibiting extensive molecular heterogeneity and several genetic alterations (Darcy and Birrer, 2010), such as MSI and LOH, which may be related to cancer development (Plisiecka-Hałasa et al., 2008). We analyzed 24 ovarian tumor samples by using 12 microsatellite markers. Six MSI cases were detected in ER $\alpha$, D5S346, and D17S250 markers. Our results showed only low-level MSI, defined as instability at $<30-40 \%$ of loci when more than 5 markers are used (Kuligina et al., 2007), suggesting that this type of MSI is an event more frequent than high-level MSI (instability at $\geq 30-40 \%$ of loci) in ovarian cancer (Kuligina et al., 2007). In accordance with our results, data reported by Sood et al. (2001) also showed that low-level MSI is more frequent than high-level MSI in a study of 109 ovarian tumors.

In agreement with the results of previous reports, LOH was more frequent than MSI in ovarian cancer (Allen et al., 2000; Bozzetti et al., 2004; Plisiecka-Hałasa et al., 2008), being detected in 7 markers (AR, CYP11, D10S197, D3S1611, ER $\alpha$, D5S346, and D17S250) and in 8 ovarian cancer samples (33.3\%). However, some samples showed LOH in more than 1 locus simultaneously.

D17S250 LOH was correlated with tumor histological type. This marker is used in hereditary non-polyposis colorectal cancer syndrome, which is associated with ovarian cancer. Hereditary non-polyposis colorectal cancer syndrome is the 3rd leading cause of hereditary ovarian cancer (Pal et al., 2008). Approximately 10 to $15 \%$ of hereditary ovarian cancers are found in patients with this syndrome (Aysal et al., 2012). However, D17S250 is centromeric to the breast cancer 1 gene, which is a tumor suppressor gene; therefore, breast cancer 1 or other genes on chromosome 17q may be involved in ovarian cancer carcinogenesis. $\mathrm{LOH}$ on chromosome $17 \mathrm{q}$ has been previously associated with the development of ovarian cancer in elderly patients, especially high-grade serous or mixed endometrioid-serous carcinomas (Garcia et al., 2000).

In conclusion, we observed that MSI and LOH frequencies varied among the studied markers. Nevertheless, LOH was observed in a greater number of markers than those displaying MSI. Our data support that LOH is a more frequent event than MSI in ovarian cancer. 


\section{ACKNOWLEDGMENTS}

Part of this study was sponsored by Fibria Celulose. L.N.R. Alves was supported by a Conselho Nacional de Desenvolvimento Científico e Tecnológico scholarship. E.V. Wolfgramm was supported by a FAPES Ph.D. scholarship.

\section{REFERENCES}

Allen HJ, DiCioccio RA, Hohmann P, Piver MS, et al. (2000). Microsatellite instability in ovarian and other pelvic carcinomas. Cancer Genet. Cytogenet. 117: 163-166.

Ando Y, Iwase H, Ichihara S, Toyoshima S, et al. (2000). Loss of heterozygosity and microsatellite instability in ductal carcinoma in situ of the breast. Cancer Lett. 156: 207-214.

Aysal A, Karnezis A, Medhi I, Grenert JP, et al. (2012). Ovarian endometrioid adenocarcinoma: incidence and clinical significance of the morphologic and immunohistochemical markers of mismatch repair protein defects and tumor microsatellite instability. Am. J. Surg. Pathol. 36: 163-172.

Bandiera E, Franceschini R, Specchia C, Bignotti E, et al. (2012). Prognostic significance of vascular endothelial growth factor serum determination in women with ovarian cancer. ISRN Obstet. Gynecol. 2012: 245756.

Boland CR, Thibodeau SN, Hamilton SR, Sidransky D, et al. (1998). A National Cancer Institute Workshop on Microsatellite Instability for cancer detection and familial predisposition: development of international criteria for the determination of microsatellite instability in colorectal cancer. Cancer Res. 58: 5248-5257.

Bozzetti C, Bortesi B and Merisio C (2004). Loss of heterozygosity (LOH) in ovarian cancer. Int. J. Gynaecol. Obstet. 85: 294-295.

Darcy KM and Birrer MJ (2010). Translational research in the Gynecologic Oncology Group: evaluation of ovarian cancer markers, profiles, and novel therapies. Gynecol. Oncol. 117: 429-439.

Ferlay J, Shin HR, Bray F, Forman D, et al. (2010). GLOBOCAN 2008 v2.0, Cancer Incidence and Mortality Worldwide: IARC CancerBase No. 10. International Agency for Research on Cancer. Lyon, France. Available at [http://globocan. iarc.fr]. Accessed October 1, 2012.

Galindo CL, McIver LJ, Tae H, McCormick JF, et al. (2011). Sporadic breast cancer patients' germline DNA exhibit an AT-rich microsatellite signature. Genes Chromosomes Cancer 50: 275-283.

Garcia A, Bussaglia E, Machin P, Matias-Guiu X, et al. (2000). Loss of heterozygosity on chromosome 17q in epithelial ovarian tumors: association with carcinomas with serous differentiation. Int. J. Gynecol. Pathol. 19: 152-157.

Helleman J, van Staveren IL, Dinjens WN, van Kuijk PF, et al. (2006). Mismatch repair and treatment resistance in ovarian cancer. BMC Cancer 6: 201

Huan Z, Nakayama K, Nakayama N, Ishibashi M, et al. (2008). Genetic classification of ovarian carcinoma based on microsatellite analysis: relationship to clinicopathological features and patient survival. Oncol. Rep. 19: 775-781.

Inca (2012). Instituto Nacional de Câncer. Available at [http://www2.inca.gov.br/wps/wcm/connect/tiposdecancer/site/ home/ovario]. Accessed October 1, 2012.

Instituto Nacional de Câncer José Alencar Gomes da Silva (2011). Estimativa 2012: Incidência de Câncer no Brasil, Instituto Nacional de Câncer José Alencar Gomes da Silva.

Jemal A, Bray F, Center MM, Ferlay J, et al. (2011). Global cancer statistics. CA Cancer J. Clin. 61: 69-90.

Kuligina ES, Grigoriev MY, Suspitsin EN, Buslov KG, et al. (2007). Microsatellite instability analysis of bilateral breast tumors suggests treatment-related origin of some contralateral malignancies. J. Cancer Res. Clin. Oncol. 133: 57-64.

Pal T, Permuth-Wey J and Sellers TA (2008). A review of the clinical relevance of mismatch-repair deficiency in ovarian cancer. Cancer 113: 733-742.

Plisiecka-Hałasa J, Dansonka-Mieszkowska A, Kraszewska E, Dańska-Bidzińska A, et al. (2008). Loss of heterozygosity, microsatellite instability and TP53 gene status in ovarian carcinomas. Anticancer Res. 28: 989-996.

Powierska-Czarny J, Miścicka-Sliwka D, Czarny J, Grzybowski T, et al. (2003). Analysis of microsatellite instability and loss of heterozygosity in breast cancer with the use of a well characterized multiplex system. Acta Biochim. Pol. 50: 1195-1203.

Shen XJ, Ali-Fehmi R, Weng CR, Sarkar FH, et al. (2006). Loss of heterozygosity and microsatellite instability at the $\mathrm{Xq} 28$ and the A/G heterozygosity of the QM gene are associated with ovarian cancer. Cancer Biol. Ther. 5: 523-528.

Skirnisdottir I, Mayrhofer M, Rydåker M, Åkerud H, et al. (2012). Loss-of-heterozygosity on chromosome 19q in earlystage serous ovarian cancer is associated with recurrent disease. BMC Cancer 12: 407.

Sood AK, Holmes R, Hendrix MJ and Buller RE (2001). Application of the National Cancer Institute international criteria for determination of microsatellite instability in ovarian cancer. Cancer Res. 61: 4371-4374. 